\title{
Karasu Nehri Su Kalitesinin Farklı Su Kalite İndeksleri Açısından Değerlendirilmesi
}

\author{
Alper ALVER $^{*}{ }^{\oplus}$, Emine BAŞTÜRK ${ }^{2} \mathbb{D}$ \\ ${ }^{1,2}$ Aksaray Üniversitesi, Mühendislik Fakültesi, Çevre Mühendisliği Bölümü, 68100, Aksaray, Türkiye
}

(Alınıș / Received: 18.02.2018, Kabul / Accepted: 11.07.2019, Online Yayınlanma / Published Online: 30.08.2019)

\author{
Anahtar Kelimeler \\ Karasu nehri, \\ Su kalite indeksi, \\ İzleme, \\ Ulusal Sanitasyon Vakfi, \\ Kanada Çevre Bakanlığı Konseyi, \\ Oregon
}

Özet: Yağışların azaldığı, tarımsal ve endüstriyel faaliyetlerin giderek arttığı İç Anadolu bölgesinde, su kaynaklarının üzerindeki baskıda her geçen gün artmaktadır. Biyolojik ihtiyaçlar, entegre çevre yönetimi ve sürdürülebilir kalkınma hedefleri için su kaynaklarının kalitesi ve miktarı önemlidir. Su kalitesini etkileyen birçok parametrenin aynı anda yorumlanarak su kalitesinin belirlenmesi hem karmaşık hem maliyetli hem de uzun zaman almaktadır. $\mathrm{Bu}$ sebeple su kalitesinin daha anlaşılabilir bir şekilde yorumlanmasını sağlayan su kalite indeksi modelleri kullanılmaktadır. $\mathrm{Bu}$ çalışmada, Aksaray İlinin önemli içme su kaynaklarından biri olan Karasu Nehri'nin su kalitesi Aralık 2015 ve Kasım 2016 tarihleri arasında bir yll süreyle izlenilmiş olup nehrin genel su kalitesi 3 farklı su kalite indeksi modeli ile değerlendirilmiştir. İçme suyu elde edilen veya elde edilmesi planlanan yüzeysel suların kalitesine dair yönetmeliğe göre $\mathrm{NH}_{4}-\mathrm{N}, \mathrm{BOI} \dot{I}_{5}, \mathrm{Co}$, fekal koliform, $\mathrm{Ba}, \mathrm{Cu}, \mathrm{Zn}$ ve çözünmüș oksijen parametrelerinin sınır değerlerini aștığı ve suyun kalitesini etkileyen ana parametreler olduğu saptanmıştır. Ayrıca su kaynağının yüzey su kalite sınıfının $\mathrm{NO}_{2}, \mathrm{~B}, \mathrm{Cd}$ ve $\mathrm{Zn}$ parametrelerine bağlı olarak "IV" olduğu tespit edilmiştir. Uygulanan model sonuçlarına göre ise Karasu Nehri'nin su kalitesi, Ulusal Sanitasyon Vakfı Su Kalite İndeksine (USV SKİ) göre "orta", Kanada Çevre Bakanlığı Konseyi Su Kalite İndeksine (KÇBK SKi) göre "kötü" ve Oregon Su Kalite İndeksine (O SKİ) göre de "kötü" seviyede olarak tespit edilmiştir.

\section{Evaluation of Karasu River Water Quality in Terms of Different Water Quality Indexes}

\section{Keywords}

Karasu river,

Water quality index,

Monitoring,

National Sanitation Foundation,

Canadian Council of Ministers of the Environment,

Oregon

\begin{abstract}
In the Central Anatolia region where precipitation decreases and agricultural and industrial activities are increasing, the pressure on water resources is increasing day by day. The quality and quantity of water resources are important for biological needs, integrated environmental management and sustainable development goals. It is both complicated and costly to determine the water quality by interpreting many parameters affecting water quality at the same time. For this reason, water quality index models are used to provide a better understanding of the water quality. In this study, the water quality of Karasu River, which is one of the important drinking water resources of Aksaray Province, was monitored between December 2015 and November 2016 for one year and the overall water quality of the river was evaluated with 3 different water quality index models. It was determined that $\mathrm{NH}_{4}-\mathrm{N}, \mathrm{BOD}_{5}, \mathrm{Co}$, fecal coliform, $\mathrm{Ba}, \mathrm{Cu}, \mathrm{Zn}$ and dissolved oxygen parameters exceed the limit values of the regulation of drinking water obtained or planned surface water quality and the main parameters affecting the quality of water. In addition, the surface water quality class of water source was determined to be "IV" depending on $\mathrm{NO}_{2}, \mathrm{~B}, \mathrm{Cd}$ and $\mathrm{Zn}$ parameters. According to the model results, the water quality of the Karasu River was "moderate" according to the National Sanitation Foundation Water Quality Index, "bad" according to the Canadian Council of Ministers of the Environment, and "bad" according to the Oregon Water Quality Index.
\end{abstract}




\section{Giriş}

Su, canlıların yaşamında en önemli doğal kaynaktır. Ekonomik ihtiyaçlar, biyolojik ihtiyaçlar ve her türlü büyüme faaliyetlerini sürdürmek için tatlı suyu tedarik etmek en önemli sorundur. Çağımızda nüfus artışı, kentleşme, sanayileşme ve yoğun tarımsal faaliyetlerden dolayı tatlı su kaynakları her geçen gün kirlenme riski ile karşı karşıya kalmakta ve azalmaktadır. Toplumsal ihtiyaçları karşılamak için yüzeysel su kaynaklarının yetersiz olması yer altı su kaynaklarının önemini daha da arttırmaktadır. Ülkemizdeki birçok il ve ilçe, içme suyu ihtiyaçlarını yeraltı ve yüzey sularından karşılamaktadır. Sucul ekosistemin devamlılığı, endüstriyel, tarımsal ve evsel kullanımların sürekliliği için su kaynaklarında düzenli olarak su kalitesinin izlenilmesi gereklidir. Su kalitesinin değerlendirilmesi, genel olarak risk içeren birçok su kalite parametresi olduğu için karmaşık bir uygulama olabilmektedir [1]. Su kaynaklarından alınan büyük hacimli örneklerde su kalitesini değerlendirmek için birçok parametrenin analiz edilmesi de kolay bir uygulama değildir [2]. Su kalitesini değerlendirmek için kullanılan geleneksel yöntemler, deneysel olarak belirlenen parametre değerlerinin mevcut yönetmelik ve/veya kılavuzlarla karşılaştırılmasına dayanmaktadır [3]. Su kalitesi indeksleri, veri hacmini büyük ölçüde en aza indiren ve su kalitesi durumunun ifadesini basitleştiren yaklaşımlardır. Su kalitesi indeksinin hesaplanması, fiziko-kimyasal ve bakteriyolojik parametrelerin sayısına bağlıdır. Lokal bölgelerin genel su kalitesini verimli bir şekilde değerlendirmek için farklı su kalitesi indeksleri geliştirilmektedir. Birçok Ulusal ve Uluslararası kuruluş su kalitesi değerlendirme ve kirlilik kontrolünde çeșitli su kalite parametrelerini dikkate alarak farklı kullanımlar için kendilerine özgü su kalitesi kriterleri tanımlamaktadırlar. Dünya çapında geliştirilen farklı su kalitesi göstergelerine örnek olarak ABD Ulusal Sağlık Hizmetleri Kurumu Su Kalite İndeksi (USV SKİ), Kanada Çevre Bakanlığı Konseyi Su Kalite İndeksi (KÇBK SKİ), Kolombiya Su Kalite İndeksi (K SKI) ve Oregon Su Kalite İndeksi (O SKİ) verilebilir [4-7]. Bu indeksler, standartlara göre farklı parametreleri karşılaştırarak su kalitesini tek bir değerde ifade etmektedirler. Dünya çapında genel olarak kabul edilmiş bir su kalite indeksi olmamasına rağmen, bazı ülkeler su kalitesi indekslerinin geliştirilmesinde birleşerek su kalitesi verilerini topluca kullanmış ve kullanmaktadır. Bu yöntem su kalitesi indekslerinin farklı bölgelerde uygulanabilirliklerini arttırmaktadır.

Genel olarak, su kalitesi indeksleri dört ana gruba ayrılmaktadır [8]. İlk olarak, genel indeksler: bu indeksler su tüketimlerini dikkate almaz ve USV SKI gibi genel su kalitesinin değerlendirilmesi amacıyla kullanılmaktadır. İkincisi, spesifik tüketim indeksleridir: suyun sinıflandırılması, Oregon ve Kolombiya indeksleri gibi içme, endüstriyel ve ekosistem koruma vb. tüketim türünün ve uygulamasının öncülerindendir [9]. Üçüncüsü, tasarım veya planlama indeksleri: su kalitesi yönetimi projelerinin planlanmasından karar verme aşamasına kadar birçok adımında yardımcı bir araç olarak kullanılmaktadır. Dördüncüsü, istatistiksel indeksler: $\mathrm{Bu}$ indeksler kişisel görüşü en aza indirerek ve istatistiksel yöntemlerin bulgularına dayanmaktadır. Verilerin değerlendirilmesinde istatistiksel yaklaşımlar kullanılmaktadır. İstatistiksel yaklaşımın önemli adımı su kalitesi gözlemlerine uygun varsayımların türetilmesidir. İlk üç indeks aynı zamanda uzman görüşü (EO) yaklaşımı olarak ta adlandırılmaktadır. Aynı su kalite parametreleri için belirlenen farklı etkinlik katsayılardan dolayı EO öznel bir yaklaşım olarak ifade edilmektedir [10]. Uzmanlar tarafından belirlenen farklı katsayılar nedeniyle nesnellik ve karşılaştırılabilirlik oranları azdır. $\mathrm{Bu}$ nedenle birçok alternatif indeks geliştirilmiştir. İndekslerin geliştirilmesinde istatistiksel yaklaşımlar kullanarak öznel varsayımlar azaltılmaya çalışılmaktadır. Ayrıca istatistiksel yaklaşımlar, su kalitesinin değerlendirmesinde önemli olarak belirlenen su kalite parametrelerinin ağırlıklı etkilerinin ortaya konulmasında da faydalıdır [11].

$\mathrm{Bu}$ çalışmada Aksaray İline içme suyu temin edilen Mamasın Baraj gölünü besleyen iki nehirden biri olan Karasu Nehrinin genel su kalitesi USV, KÇBK ve 0 SKİlerine göre değerlendirilmiştir. Bunun yanı sıra su kalite parametreleri İçme Suyu Elde Edilen veya Elde Edilmesi Planlanan Yüzeysel Suların Kalitesine Dair Yönetmelik, Yüzeysel Su Kalitesi Yönetimi Yönetmeliği ve TS 266 içme suyu standartları ve WHO kllavuzlarında yer alan sınır değerlere göre yorumlanmıştır. Yapılan değerlendirmeler sonrasında su kalitesini düşüren parametrelerin sinerjik etkisi nedeniyle ortaya çıkan su kalite sınıfı belirlenebilmiş ve çok sayıdaki parametre içerisinden olumsuz yönde en fazla etki eden parametreler istatistiki olarak tespit edilebilmiştir.

\section{Materyal ve Metot}

\subsection{Calıșma Alanı}

$34^{\circ} 20^{\prime}-34^{\circ} 38^{\prime}$ batı boylamları ve $38^{\circ} 36^{\prime}-38^{\circ} 43^{\prime}$ kuzey enlemleri arasında yer alan Karasu Nehri, Aksaray İli Gülpınar İlçesinden doğarak Mamasın Barajına dökülmekte ve yaklaşık 16,5 km²lik bir yüzey alanına sahiptir. Aksaray İlinin en büyük içme suyu kaynaklarından biri olan Karasu Nehri, yıllık ortalama 600-4200 L s ${ }^{-1}$ debiye sahiptir. Çalışma alanı Şekil 1'de gösterilmiştir.

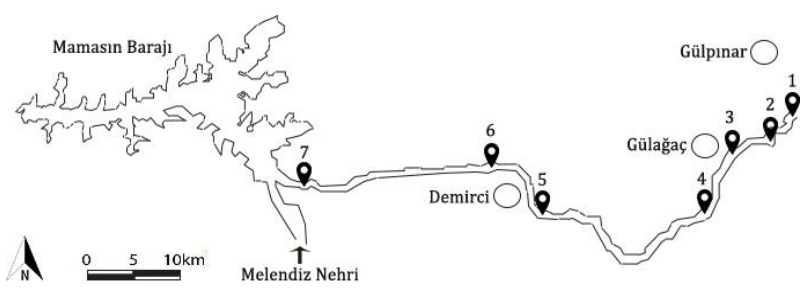

Şekil 1. Çalıșma alanının harita üzerinde gösterimi. 
12 ay süren arazi çalışmaları süresince Karasu Nehri üzerinde yer alan Gülpınar, Gülağaç ve Demirci ilçelerinin giriș ve çlkışlarından ve Karasu Nehrinin Mamasın Barajına döküldügü nokta dahil toplam 7 noktadan su örnekleri toplanmıştır. Su örnekleri ağzı kapalı steril cam numune kaplarına alınarak soğuk zincir uygulaması ile laboratuvara aktarılmıştır. Laboratuvarda analizlerine 24 saat geçmeden başlanılmıştır.

\subsection{Analitik Yöntemler}

Sıcaklık, pH, iletkenlik, toplam çözünmüş katı madde ve çözünmüş oksijen parametreleri portatif multiparametre ölçer kullanılarak, bulanıklık parametresi ise bulanıklık ölçer kullanılarak sahada analiz edilmiştir.

KOİ parametresi kapalı reflux yöntemine göre BOİ parametresi ise oksitop yöntemi ile analiz edilmiştir. Toplam azot, Shimadzu TOC-V/TNM-1 cihazı ile SM 5310 B metoduna uygun olarak ve amonyak azotu tayini ise SM $4500-\mathrm{NH}_{3} \quad \mathrm{C}$ 'ye uygun olarak spektrofotometrik olarak gerçekleştirilmiştir.Toplam Fosfor tayini de spektrofotometreik olarak SM 4500P D metoduna göre gerçekleştirilmiştir.

Anyonlar ( $\mathrm{F}, \mathrm{Cl}, \mathrm{NO}_{2}, \mathrm{NO}_{3}, \mathrm{PO}_{4}$ ve $\mathrm{SO}_{4}$ ), Dionex IC 1000 cihazı ile SM $4110 \mathrm{~B}$ metoduna göre analiz edilmiştir. Katyonlar (Al, As, B, Ba, Ca, Cd, Co, Cu, Fe, K, Mg, Mn, $\mathrm{Na}, \mathrm{Ni}, \mathrm{Pb}, \mathrm{Se}$ ve $\mathrm{Zn}$ ) ise Perkin Elmer Optima 2100 DV cihazı ile EPA 200.7 metoduna göre analiz edilmiștir.

Fekal koliform (Escherichia coli) tayinleri TS EN ISO 9308-1 metoduna göre gerçekleștirilmiştir [12, 13]. Tüm laboratuvar analizleri, Aksaray Üniversitesi Çevre Mühendisliği Laboratuvarlarında su ve atıksu değerlendirilmesinde kullanılan standart metotlara uygun olarak gerçekleștirilmiştir [14].

\subsection{Su Kalite İndeksleri}

SKI başlangıçta Amerika Birleşik Devletleri'nde Horton tarafından çözünmüş oksijen, pH, koliformlar, iletkenlik, alkalinite ve klorür gibi en yaygın kullanılan 10 su kalite parametresi seçilerek geliştirilmiştir [10]. Daha sonra bu yöntem Avrupa, Afrika ve Asya'daki birçok ülkede uygulanmaya başlamış ve kabul görmüştür. Parametrelerin ağırlıklı etkisi suyun kullanım amacına göre belirlenen parametrenin önemini yansıtmakta ve bu değerler SKİde önemli bir etkiye sahiptirler. 1970 yılında Brown grubu Horton'un indeksine benzer yeni bir SKI de geliştirmiştir [15]. Brown indeksi ise parametrelerin tekil ağırlıklı etkilerine dayanmaktadır. Son zamanlarda ise SKİ konsepti için çeşitli bilim adamları ve uzmanlar tarafından birçok değişiklik yapılmıştır $[16,17]$. Genel bir SKI yaklaşımı, aşağıdaki üç adımda açıklanan en yaygın faktörlere dayanmaktadır [18]: $\checkmark \quad$ Parametre seçimi: Suyun kullanım amacına göre uzmanların, ajansların veya devlet kurumlarının kararı ile kılavuzlarda ya da yönetmeliklerde belirtilen parametreler baz alınır. Parametrelerin oksijen seviyesi, ötrofikasyon, sağlık yönleri, fiziksel özellikleri ve su kalitesi üzerinde etkisinin önemine göre çözünmüş maddeler arasından seçilmesi önerilmektedir [19].

$\checkmark \quad$ Alt İndeks olarak kabul edilen her bir parametre için kalite fonksiyonunun (eğrisinin) belirlenmesi: Farklı konsantrasyon birimlerine sahip parametrelerin aynı şekilde değerlendirilebileceği bir ölçek olan birimsiz değerlere dönüştürülmesidir.

$\checkmark$ Matematiksel ifade ile alt indekslerin birleştirilmesi: Genellikle aritmetik veya geometrik ortalamalar alınarak yapılmaktadır.

\subsubsection{Ulusal sanitasyon vakfı su kalite indeksi (USV SKi)}

Parametrelerin seçilmesinde, ortak bir ölçek geliștirilmesinde ve ağırlık etkilerinin belirlenmesinde çalışmalar büyük bir titizlikle yürütülerek USV SKİ yöntemi geliştirilmiştir. Çalışmalar Ulusal Sanitasyon Vakfı tarafından desteklendiğinden dolayı bu yöntem USV SKİ olarak isimlendirilmiş ve kritik derece kirlenmiş çeşitli su kütlelerinin SKİlerini hesaplamak için kullanılmıştır. Farklı su kaynaklarının kalitesini karşılaştırmak için önerilen bu yöntem sıcaklık, pH, bulanıklık, fekal koliform, çözünmüş oksijen, biyokimyasal oksijen ihtiyacı (BOİ), toplam fosfat, nitrat ve toplam çözünmüş katı madde olmak üzere 9 adet su kalite parametresine dayanmaktadır $[15,20]$. Su kalite parametrelerinin verileri sayısal bir $Q_{i}$ değerinin elde edildiği ağırlıklı etki eğrisi grafiğine aktarılmaktadır. USV SKİ için matematiksel ifade Denklem 1'de verilmiştir.

$$
U S V S K \dot{\mathrm{I}}=\sum_{i=1}^{n} Q_{i} W_{i}
$$

Burada; $\mathrm{Q}_{\mathrm{i}}=\mathrm{su}$ kalitesi parametresi için alt indeks; $\mathrm{W}_{\mathrm{i}}=\mathrm{su}$ kalitesi parametresiyle ilişkili ağırlık ve $\mathrm{n}=\mathrm{su}$ kalitesi parametrelerinin sayısıdır. $Q_{i}$ değerleri, incelenen dokuz parametrenin konsantrasyonlarına karşılık gelen değerler olup, bu değerlerin okunacağ abaklar "Field Manual for Water Quality Monitoring" adlı kitapta yer almaktadır [21]. Denklem 1 de bahsedilen su kalitesi parametresiyle ilișkili ağırlıklı etki $\left(\mathrm{W}_{\mathrm{i}}\right)$ değerleri Tablo 1'de verilmiştir [22].

\subsubsection{Kanada konseyi çevre bakanlığı su kalite indeksi (KÇBK SKİ)}

Kanada yönetimi tarafından hem yönetmelik ve kanunlarda kullanılan hem de halkın bilgilendirilmesi için geliştirilen KÇBK SKI su kalitesi sınıfını ölçütlendirmek için formüle edilmiş tutarlı bir 
Tablo 1. Ulusal sanitasyon vakfi su kalite indeksinde kullanılan parametrelere ait ağırlıklı etki değerleri.

\begin{tabular}{lc}
\hline Parametre & Ağırlık değeri (Wi) \\
\hline Çözünmüş oksijen & 0,17 \\
Fekal Koliform & 0,15 \\
pH & 0,12 \\
$\mathrm{BOI}_{5}$ & 0,1 \\
$\mathrm{NO}_{3}$ & 0,1 \\
$\mathrm{PO}_{4}$ & 0,1 \\
Sıcaklık & 0,1 \\
Bulanıklık & 0,08 \\
Toplam çözünmüş madde & 0,08 \\
$\sum W_{i}$ & 1,00 \\
\hline
\end{tabular}

yöntemdir. Kanada Çevre Bakanlığı Konseyi altında kurulan bir komite, çeşitli ülkelerdeki pek çok su kurumu tarafından ufak tefek değișikliklerle uygulanabilecek KÇBK SKİ'yi geliştirmiştir [6, 23, 24]. $\mathrm{Bu}$ yöntem, suda yaşayan canlıların korunmasına yönelik yüzey suyunun spesifik kurallara uygun olarak değerlendirilmesi için geliştirilmiştir. Parametreler bir numune alma noktasından diğerine değișebilmekte ve örnekleme protokolü en az dört kez örneklenmiş en az dört parametre gerektirmektedir $[25,26]$. KÇBK SKİ yönteminde indeks değerleri Denklem 2 kullanılarak hesaplanmıştır [27].

$$
K C ̧ B K S K \dot{\mathrm{I}}=100-\frac{\sqrt{F_{1}^{2}+F_{2}^{2}+F_{3}^{2}}}{1,732}
$$

Kapsam (F1) = Başarısız değişkenlerin sayısıdır ve Denklem 3 ile ifade edilir.

$$
F_{1}=100 * \frac{\text { Başarısız parametre sayısı }}{\text { Toplam parametre sayısı }}
$$

Frekans $(\mathrm{F} 2)=$ Hedeflere ulaşılma sayısıdır ve Denklem 4 ile ifade edilir.

$$
F_{2}=100 * \frac{\text { Başarısız analiz sayısı }}{\text { Toplam analiz sayısı }}
$$

Genlik (F3) = Başarısız analiz değeridir ve üç adımda çözümlenir (Denklem 5-7).

$$
\begin{aligned}
& \text { (a) } \text { sapma }_{i}=\frac{\text { Başarısız analiz değeri }}{i_{i}}-1 \\
& \text { (b) } n s e=\frac{\sum_{i=1}^{n} \text { sapma }_{i}}{\text { Toplam analiz sayısı }} \\
& \text { (c) } F_{3}=\frac{n s e}{0,01 * n s e+0,01}
\end{aligned}
$$

Elde edilen SKI değeri Tablo 2'ye göre değerlendirilmiştir. Hesaplamada kullanılan hedef analiz değeri (Çalışma alanının bulunduğu ülkenin yönetmelik sınır değerleri) Tablo 3'te verilmiştir.

\subsubsection{Oregon su kalite indeksi (O SKI)}

Oregon su kalite indeksi yöntemi, Oregon bölgesinde bulunan akarsuların genel su kalitesini değerlendirmek ve bu yöntemin diğer coğrafi bölgelerde uygulanmasını sağlamak için bir puanlama sistemi olușturmakta ve sekiz su kalitesi parametresini tek bir sayıda birleștirmektedir. Bu yöntemde ele alınan parametreler sıcaklık, çözünmüş oksijen, biyokimyasal oksijen ihtiyacl, pH, amonyak ve nitrat azotu, toplam fosfor, toplam katı madde ve fekal koliformdur $[19,28]$. O SKİ, Delphi metodunu parametre seçimi için kullanan USV SKİ'den sonra tasarlanmıştır. Yasal olarak zorunlu olan su kalitesi izleme çalışmalarında su kalitesi durumunu ve kirlilik eğilimlerini ifade etmektedir. İndeks, parametrelerin ağırlıklı etkilerinin belirlenmesinde yasal limitleri dikkate almaz ve harmonik ortalamalarını kullanmaktadır. Bu SKİ yönteminin matematiksel ifadesi Denklem 8'de verilmiştir.

$$
O S K \dot{\mathrm{I}}=\sqrt{\frac{n}{\sum_{i=1}^{n} \frac{1}{S I_{i}^{2}}}}
$$

$\mathrm{Bu}$ denklemde, $\mathrm{n}=$ alt indis sayısı ve $\mathrm{SI}=$ parametrenin alt indeksidir. Ayrıca, bu 0 SKİnin derecelendirme ölçeği de Tablo 1'de verilmiştir [29]. Parametrelerin alt indeks değerleri, her parametrenin konsantrasyonlarına karşılık gelen değerler olup, bu değerlerin okunacağı abaklar ilgili kaynakta belirtilmiştir [29].

USV, KÇBK ve O SKİ yöntemlerinde su kalitesi değerlerine karşılı gelen su kalitesi derecelendirilmeleri Tablo 2'de verilmiștir.

Tablo 2. Farklı su kalite indeksi yöntemlerine göre su kalitesi değerleri.

\begin{tabular}{cc}
\hline SKI Değeri & $\begin{array}{c}\text { Su Kalite } \\
\text { Derecelendirmesi }\end{array}$ \\
\hline $\begin{array}{c}\text { Ulusal Sanitasyon Vakfı Su Kalite İndeksi } \\
91-100\end{array}$ & Mükemmel \\
$71-90$ & İyi \\
$51-70$ & Orta \\
$26-50$ & Kötü \\
$0-25$ & Çok kötü \\
Kanada Çevre Bakanlığı Konseyi Su Kalite \\
\multicolumn{2}{c}{ İndeksi } \\
$95-100$ & Mükemmel \\
$80-94$ & İyi \\
$60-79$ & Uygun \\
$45-59$ & Marjinal \\
$0-44$ & Kötü \\
Oregon Su Kalite İndeksi \\
$90-100$ & Mükemmel \\
$85-89$ & İyi \\
$80-84$ & Uygun \\
$60-79$ & Kötü \\
$0-59$ & Çok kötü \\
&
\end{tabular}




\section{Bulgular}

\subsection{Yüzeysel Su Karakterizasyonu}

Aksaray İlinin önemli içme suyu kaynaklarından biri olan Karasu Nehrinde yapılan izleme çalışmasında, yedi farklı numune alma noktasından Aralık 2015Kasım 2016 tarihleri arasında alınan örneklerde 35 parametrenin analizi yapılmıștır. Analiz edilen parametrelerin minimum, maksimum, ortalama ve standart sapma değerleri Tablo 3'te verilmiștir.

Tablo 3'te verilen parametreler arasında fiziksel parametreler $(\mathrm{pH}$, iletkenlik, bulanıklık), kimyasal oksijen ihtiyacl, biyokimyasal oksijen ihtiyacl, çözünmüş oksijen), besi maddeleri $\left(\mathrm{NH}_{3}-\mathrm{N}, \mathrm{NO}_{2}, \mathrm{NO}_{3}\right.$, P04), diğer anyonik ve katyonik maddeler $\left(\mathrm{F}, \mathrm{Cl}_{1} \mathrm{SO}_{4}\right.$, $\mathrm{Ba}, \mathrm{Ca}, \mathrm{K}, \mathrm{Mg}, \mathrm{Na}$ ) ve ağır metaller ( $\mathrm{Al}, \mathrm{As}, \mathrm{B}, \mathrm{Cd}, \mathrm{Co}$, $\mathrm{Cu}, \mathrm{Fe}, \mathrm{Mn}, \mathrm{Ni}, \mathrm{Pb}, \mathrm{Se}, \mathrm{Zn}$ ) yer almaktadır. Belirlenen bu parametreler su kalitesinin izlenilmesinde önemli olan ve tüketici üzerinde doğrudan ve/veya dolaylı olarak etkisi olan parametrelerdir.

Yüzeysel Su Kalitesi Yönetimi Yönetmeliği (YSKYY) baz alınarak su kalitesi incelenecek olursa toplam azot, toplam fosfor, $\mathrm{NH}_{4}-\mathrm{N}, \mathrm{KOI}, \mathrm{BOI} \dot{I}_{5}, \mathrm{Mn}$ ve Se parametrelerinin yönetmelik sınır değerlerini bazı zamanlarda aştığı görülmektedir. Mevsim değişimlerin $\mathrm{NO}_{2}, \mathrm{NO}_{3}, \mathrm{~B}, \mathrm{Cd}, \mathrm{Co}, \mathrm{Zn}$ ve fekal koliform konsantrasyonlarını olumsuz etkilemesi neticesinde su kaynağının kalite sınıfı III ve IV'e kadar düşebilmektedir. Ayrıca bu parametreler TS 266 'da belirtilen sınır değerleri de aşmaktadır. Yani su kalitesinin bozulması ile birlikte içilebilirliği azalmakta ve arıtım ihtiyacı artmaktadır. Su kalitesinin düşmesinin bir sebebi de evsel ve endüstriyel atıksu kanallarından nehre sızma ve deşarjların olması ve nehir etrafından yapılan çeşitli tarımsal faaliyetlerden kaynaklandığı düşünülmektedir.

Karasu Nehrinde organik madde değerlerinin yüksek olması suyun kaynak bölgesinin sulak alan özelliğine sahip olmasıyla açılanabilir. Sulak alanlar tipik olarak organik zenginliği yüksek ortamlar olduğundan, Karasu Çayındaki yüksek organik madde derişimin doğal kökenli olduğu söylenebilir. Bu tür doğal organik madde içeren kaynaklardan içme suyu temini tat, koku ve kanserojen dezenfeksiyon yan ürünleri oluşturma potansiyelinin yüksek olması sebebiyle insan sağlığı açısından risk oluşturmaktadır.

Alg patlaması (ötrofikasyon)'na sebep olan temel parametrelerden birisi olan azot, çeşitli formlarında (amonyum, nitrit, nitrat, toplam azot) izlenmiştir. Bu formlar ötrofikasyonun yanında, toksisite (amonyum), insan sağlığı (nitrit-nitrat) ve su kalitesi (arıtmada oluşan kloraminler) açılarından önem taşımaktadır.

Karasu Nehrinde kurak ve yağışlı dönemlerin her ikisinde amonyum ve nitrite rastlanmıştır. Sularda bu tür maddelerin varlığı; ortama uzun zamanlarda azotlu organik madde girişinin olduğunu gösterir.

\subsection{Su Kalite İndeks Modelleri}

Birçok parametrenin takibinin yapıldığı izlenebilirlik çalışmalarında su kaynağı üzerinde etkili olan parametreleri belirlemek amacıyla farklı istatistiki metotlara başvurulmaktadır. İstatistiki hesaplarla parametrelerinin öneminin belirlenmesi ve su kaynağının bu parametreler üzerinden derecelendirilmesi çoğu zaman su kalite indeksi modelleri ile yapılmaktadır. Literatürde bu konuda yapılan farklı çalışmalar mevcuttur. Debels vd., (2005), su kalite indeksinde BOİ parametresi yerine zaman ve maliyet açısından KOİ parametresini kullanmışlardır. Modifiye edilen SKİ değeri ile orijinal SKI değeri arasında çok fark olmadığını kanıtlamışlardır $\left(\mathrm{R}^{2}=0,97\right)$ [3]. Karami vd. (2009), su kalitesinin belirlenmesinde kullanılan kimyasal indikatörler ile SKİ arasında olan ilişkiyi araștırmışlardır. Bu çalışma sorasında, SKI ve Ç.O., KOİ, BOİ 5 , fosfat arasında kübik etki, SKİ ve $\mathrm{pH}$, sıcaklık, toplam katı madde arasında üstel bir ilişki gözlemlemişlerdir [30].

$\mathrm{Bu}$ çalışmada ise Karasu Nehrinin 12 ay boyunca izlenilmesi sonrasında elde edilen veri setine USV, KÇBK ve O SKİ modelleri uygulanarak sonuçlar istatistiki olarak yorumlanmıștır.

\subsubsection{Ulusal sanitasyon vakfı su kalite indeksi}

USV'nin önermiş olduğu indekste dokuz su kalite parametresi kullanılarak su kaynağı "çok kötü" ile "mükemmel" arasında 5 sinıfa ayrilabilmektedir. Karasu Nehrinin aylık periyotlarda numune alma noktası bazında USV SKİ değerlerinin değişimi Tablo 4'te özetlenmiştir. USV SKİ değerlerinin mevsimsel ortalamaları da Șekil 2'de gösterilmiștir.

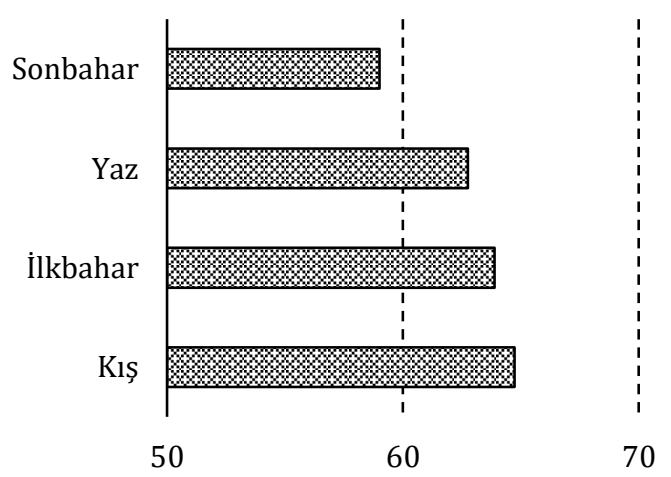

Şekil 2. USV SKİ’nin mevsime göre değişimi. 
Tablo 3. Su kalite parametrelerinin istatistiki verileri ve sınır değerleri. (

\begin{tabular}{|c|c|c|c|c|c|c|c|}
\hline Parametre & $\begin{array}{c}\text { En } \\
\text { Yüksek }\end{array}$ & $\begin{array}{c}\text { En } \\
\text { Düşük }\end{array}$ & Ortalama & $\begin{array}{c}\text { Standart } \\
\text { Sapma }(n=84) \\
\end{array}$ & $\begin{array}{c}\text { Sinır } \\
\text { Değerler }\end{array}$ & $\begin{array}{l}\text { Yüzeysel Su } \\
\text { Kalite Sınıfıd }\end{array}$ & $\begin{array}{c}\text { Kullanılan } \\
\text { SKİ }\end{array}$ \\
\hline Toplam Azot & 4,147 & 0,285 & 2,001 & 0,814 & $<3,500^{d}$ & - & Oregon \\
\hline Toplam Fosfor & 0,177 & 0,002 & 0,077 & 0,040 & $<0,03^{d}$ & II & Oregon \\
\hline $\mathrm{NH}_{4}-\mathrm{N}$ & 1,527 & 0,034 & 0,217 & 0,288 & $0,05^{a}-0,20^{d}$ & II & KÇBK \\
\hline KOİ & 45,38 & $<10,00$ & 9,417 & 8,094 & $15,00^{e}-25,00^{d}$ & I & KÇBK \\
\hline BOİं5 & 27,23 & $<3,000$ & 5,650 & 4,856 & $<3,0^{\mathrm{a}}-4,0^{\mathrm{d}}$ & II & USV, Oregon \\
\hline $\mathrm{F}$ & 0,919 & 0,029 & 0,379 & 0,197 & $1,00^{d}-1,50^{e}$ & I & KÇBK \\
\hline $\mathrm{Cl}$ & 75,85 & 28,24 & 36,73 & 9,004 & $200,0^{\mathrm{a}}$ & - & KÇBK \\
\hline $\mathrm{NO}_{2}$ & 1,705 & 0,071 & 0,356 & 0,276 & $0,500^{e}$ & IV & KÇBK \\
\hline $\mathrm{NO}_{3}$ & 33,50 & 2,389 & 10,72 & 5,258 & $50,00^{\mathrm{e}}$ & III & USV, KÇBK \\
\hline $\mathrm{PO}_{4}$ & 0,092 & $<0,005$ & 0,041 & 0,026 & $0,400^{\mathrm{e}}$ & - & USV, KÇBK \\
\hline $\mathrm{SO}_{4}$ & 52,36 & 9,140 & 21,31 & 9,874 & $250,0^{\mathrm{e}}$ & - & KÇBK \\
\hline $\mathrm{Al}$ & 0,106 & 0,004 & 0,044 & 0,022 & $0,200^{e}-\leq 0,300^{d}$ & I & KÇBK \\
\hline As & 0,039 & 0,011 & 0,018 & 0,005 & $0,010^{\mathrm{e}}-\leq 0,020^{\mathrm{d}}$ & I & KÇBK \\
\hline B & 9,781 & 0,202 & 1,628 & 2,500 & $0,001^{\mathrm{e}}->1,000^{\mathrm{d}}$ & IV & KÇBK \\
\hline $\mathrm{Ba}$ & 0,619 & $<0,005$ & 0,084 & 0,110 & $0,100^{\mathrm{a}}-\leq 1,000^{\mathrm{d}}$ & I & KÇBK \\
\hline $\mathrm{Ca}$ & 202,3 & 12,83 & 66,64 & 24,82 & $1000^{c}$ & - & KÇBK \\
\hline $\mathrm{Cd}$ & 0,091 & $<0,005$ & 0,011 & 0,028 & $0,005^{e}->0,007 d$ & IV & KÇBK \\
\hline Co & 0,411 & $<0,005$ & 0,063 & 0,109 & $0,010^{a}-0,010^{d}$ & III & KÇBK \\
\hline $\mathrm{Cu}$ & 0,036 & $<0,005$ & 0,005 & 0,007 & $\leq 0,020^{\mathrm{d}}-0,020^{\mathrm{a}}$ & I & KÇBK \\
\hline $\mathrm{Fe}$ & 0,422 & $<0,005$ & 0,139 & 0,148 & $0,200^{\mathrm{e}}-\leq 0,300^{\mathrm{d}}$ & I & KÇBK \\
\hline $\mathrm{K}$ & 33,30 & 4,482 & 13,00 & 5,031 & $3700^{\mathrm{b}}$ & - & KÇBK \\
\hline $\mathrm{Mg}$ & 92,31 & 6,790 & 35,83 & 14,41 & $200,0^{c}$ & - & KÇBK \\
\hline $\mathrm{Mn}$ & 0,478 & $<0,005$ & 0,042 & 0,077 & $0,050^{e}-0,100^{d}$ & I & KÇBK \\
\hline $\mathrm{Na}$ & 147,7 & 23,44 & 59,04 & 19,85 & $200,0^{\mathrm{e}}$ & - & KÇBK \\
\hline $\mathrm{Ni}$ & 0,092 & $<0,005$ & 0,018 & 0,020 & $\leq 0,020^{d}-0,020 \mathrm{e}$ & I & KÇBK \\
\hline $\mathrm{Pb}$ & 0,052 & $<0,005$ & 0,020 & 0,017 & $\leq 0,010^{\mathrm{d}}-0,010^{\mathrm{e}}$ & I & KÇBK \\
\hline $\mathrm{Se}$ & 0,017 & $<0,005$ & 0,007 & 0,004 & $\leq 0,010^{d}$ & I & KÇBK \\
\hline $\mathrm{Zn}$ & 1,326 & 0,017 & 0,492 & 0,296 & $\leq 0,100^{\mathrm{d}}-0,500^{\mathrm{a}}$ & IV & KÇBK \\
\hline $\mathrm{pH}^{*}$ & 8,650 & 6,290 & 7,593 & 0,660 & $6.5-8.5^{\mathrm{d}}$ & I & USV, Oregon, KÇBK \\
\hline İletkenlik* & 936,0 & 449,0 & 589,2 & 94,19 & $<400^{d}$ & II & KÇBK \\
\hline TÇKM & 627,1 & 300,8 & 394,8 & 63,11 & - & - & USV, Oregon \\
\hline Ç. Oksijen & 14,73 & 3,090 & 8,526 & 2,447 & $>8,000^{a, d}$ & I & USV, Oregon KÇBK \\
\hline Bulanıklık* & 54,68 & 0,130 & 7,757 & 9,492 & $5,000^{e}$ & - & USV, KÇBK \\
\hline Sicaklık* & 27,40 & 7,700 & 16,43 & 4,869 & $20,00^{\mathrm{e}}$ & I & USV, Oregon, KÇBK \\
\hline F Koliform* & 551,0 & 8,000 & 287,5 & 90,10 & $50,00^{a}$ & III & USV, Oregon, KÇBK \\
\hline
\end{tabular}

Tablo 4. Numune alma noktası bazında USV SKİ değerlerinın aylık değișimi.

\begin{tabular}{ccccccccccccc}
\hline$\#$ & Aralık & Ocak & Şubat & Mart & Nisan & Mayıs & Haz. & Tem. & Ağu. & Eylül & Ekim & Kasım \\
\hline \multirow{2}{*}{1} & 58,956 & 55,116 & 58,827 & 57,902 & 60,437 & 60,528 & 60,620 & 54,428 & 66,705 & 60,300 & 49,445 & 54,201 \\
& Orta & Orta & Orta & Orta & Orta & Orta & Orta & Orta & Orta & Orta & Kötü & Orta \\
\cline { 2 - 12 } 2 & 58,999 & 61,945 & 65,157 & 63,624 & 66,510 & 68,335 & 70,160 & 65,030 & 66,733 & 57,404 & 61,695 & 60,347 \\
2 & Orta & Orta & Orta & Orta & Orta & Orta & Iyi & Orta & Orta & Orta & Orta & Orta \\
\cline { 2 - 12 } & 61,965 & 66,776 & 72,248 & 66,664 & 66,080 & 68,120 & 70,161 & 62,742 & 61,743 & 53,039 & 63,558 & 62,762 \\
\multirow{2}{*}{3} & Orta & Orta & Iyi & Orta & Orta & Orta & Iyi & Orta & Orta & Orta & Orta & Orta \\
\hline \multirow{2}{*}{4} & 67,755 & 69,481 & 67,067 & 65,984 & 62,783 & 63,474 & 64,164 & 62,946 & 63,855 & 57,480 & 68,860 & 68,307 \\
& Orta & Orta & Orta & Orta & Orta & Orta & Orta & Orta & Orta & Orta & Orta & Orta \\
\hline \multirow{2}{*}{5} & 68,337 & 71,555 & 68,208 & 64,753 & 64,267 & 64,806 & 65,345 & 63,503 & 59,999 & 66,120 & 67,384 & 67,860 \\
& Orta & Iyi & Orta & Orta & Orta & Orta & Orta & Orta & Orta & Orta & Orta & Orta \\
\hline \multirow{2}{*}{6} & 63,013 & 66,829 & 63,597 & 63,583 & 62,235 & 63,397 & 64,558 & 56,050 & 59,791 & 50,009 & 58,643 & 60,828 \\
& Orta & Orta & Orta & Orta & Orta & Orta & Orta & Orta & Orta & Orta & Orta & Orta \\
\hline \multirow{2}{*}{7} & 65,688 & 66,941 & 61,084 & 65,843 & 63,656 & 61,861 & 60,065 & 59,765 & 59,697 & 59,353 & 59,432 & 62,560 \\
& Orta & Orta & Orta & Orta & Orta & Orta & Orta & Orta & Orta & Orta & Orta & Orta \\
\hline
\end{tabular}

Ulusal Sanitasyon Vakfı su kalite indeks modeline göre Karasu Nehri mevsimsel olarak değerlendirildiğinde "orta" derece su sınıfında olduğu gözlemlenmiștir. USV SKİ modelinde incelenen 9 parametreden; $\mathrm{BOI}_{5}$, nitrat, toplam çözünmüş madde, çözünmüş oksijen, bulanıklık parametrelerinin modelin üzerinde etkisinin az olduğu, fosfat, $\mathrm{pH}$,
Sicaklık ve fekal koliform parametrelerinin ise model üzerinde daha etkili olduğu sonucuna varılmıştır. Tablo 5 incelendiğinde, nehrin 4,6 ve 7 numaralı numune alma noktalarındaki (Gülağaç ve demirci çıkış noktaları) USV SKİ değerleri benzer olup alınan aylık numunelerin hepsinde "orta" derecede olduğu gözükmektedir. 1 numaralı numune alma noktasında 
(Gülpınar giriș) USV SKİ değerlerinin büyük çoğunluğunun "orta" derecede, sadece Ekim ayında "kötü" olduğu fakat skalaya bakıldığında "orta" seviyeye çok yakın olduğu gözlenmiştir. Ayrıca diğer noktalarda zaman zaman bazı aylarda "iyi" seviyede olduğu gözükmektedir. Fakat bu durumlar istisnai olmakla beraber, genel olarak karasu nehrinin USV SKI puanının "kötü" seviyededir. Bu durum, zaman zaman parametreler değişiklik gösterse de parametrelerin azalması/artmasının nehrin su kalitesinin değerinin değişmesini etkilememesi ile açıklanabilmektedir. USV SKI değerlerinın "kötü" seviyede olması, numune alım noktalarının Aksaray'ın çeşitli ilçe ve köylerine yakın olması ve bu yerleşkelerde sürdürülen tarımsal faaliyetler ve nehir sularına karışan fosseptik çukurlarından sızan sulardan kaynaklandığı düşünülmektedir.

\subsubsection{Kanada çevre bakanlığı konseyi su kalite indeksi}

TS 266'da yer alan su kalite parametreleri KÇBK SKİye göre değerlendirildiğinde ise $\mathrm{Al}, \mathrm{Cd}, \mathrm{Pb}, \mathrm{Zn}$ ve çözünmüş oksijen parametrelerinin marjinal seviyede olduğu, As ve fekal koliform parametrelerinin ise kötü seviyede olduğu Şekil 3'teki grafikte görülmektedir. Marjinal ve kötü seviyede olan kirleticiler arasında Al haricindeki parametrelerin yönetmelik sınır değerlerini aştığl dolayısıyla KÇBK SKİ modelinin genel anlamda tutarlı sonuçlar verdiği görülmektedir. KÇBK SKİ modelinde marjinal seviyenin üzerinde çlkan fakat Tablo 3'te sınır değerleri aşan diğer parametrelerin model üzerinde etkisinin az olduğu düşünülmektedir. Suda yaşayan canlıların korunmasına yönelik olarak marjinal ve kötü seviyedeki bu parametrelerin iyileștirilmesi gerekmektedir.

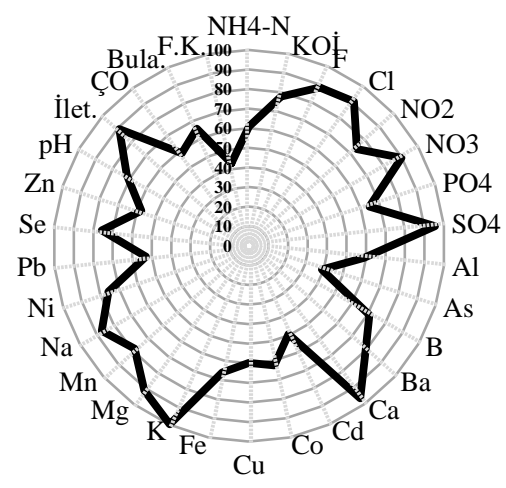

Şekil 3. Su kalite parametrelerinin KÇBK SKİ değerleri

\subsubsection{Oregon su kalite indeksi}

Oregon su kalite indeksinde belirtilen 8 su kalite parametresi puanlama sistemine tabii tutulduğunda ortalama olarak kış aylarında 43,740 \pm 18,271, ilkbahar aylarında 42,568 $\pm 16,523$, yaz aylarında $59,483 \pm 18,566$ ve sonbahar aylarında 51,711 \pm 18,844 değerleri elde edilmiştir (Şekil 4). En yüksek değerlerin yaz aylarında, en düşük değerlerin ise ilkbahar aylarında ortaya çıktığı görülmektedir. Su kaynağının genel kalite durumunun, izleme çalışması boyunca çok kötü seviyeden kötü seviyeye iyileștiği gözlemlenmiştir. Buna rağmen su kaynağının genel anlamda kötü seviyede $(49,875 \pm 19,466)$ olduğu söylenebilir. O SKİ modeli incelendiğinde ise bazı parametrelerin artması ve/veya azalmasının su kalite indeks değerini etkilemediği, bazı parametrelerin ise direkt olarak etkili olduğu gözlemlenmiștir. Numune alma noktası bazında aylık periyotlarda hesaplanan 0 SKİ değerleri Tablo 5'te özetlenmiștir.

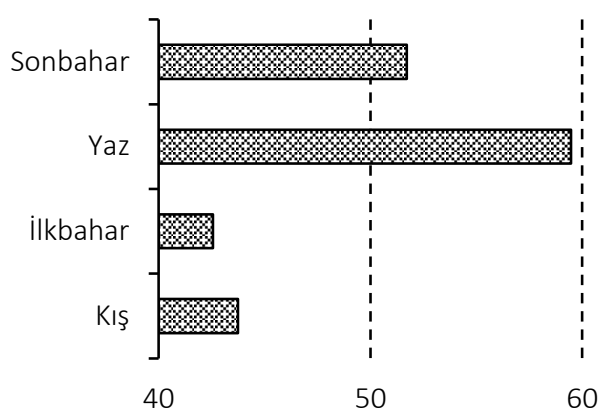

Şekil 4. Oregon SKİnin mevsime göre değişimi.

Tablo 5 incelendiğinde numune alınan tüm noktalarda ve tüm aylarda O SKİ değerlerinin "kötü" ve "çok kötü" seviyede olduğu gözlemlenmiştir. Oregon su kalitesi, genel olarak yüzme, balıkçlık gibi rekreasyonel amaçlı su kalitesi hakkında bilgiler veren bir indekstir ve BOİ ${ }_{5}$, toplam azot, pH, TÇKM, çözünmüş oksijen, toplam fosfor, sıcaklık ve fekal koliform parametrelerinin karelerinin harmonik ortalamaları ele alınarak hesaplanmaktadır. Hesaplamalarda genel olarak etkili olan parametre Alınan tüm örneklerde "kötü" ve "çok kötü" olmasının temel sebebi Fekal koliform miktarının yüksek olmasıdır. $\mathrm{Bu}$ durum ise Karasu Nehrinin mevcut haliyle 0 SKİye göre rekreasyonel amaçlı kullanamayacağının göstergesidir. Fekal kirliliğin fosseptik çukurlarından sızan suların nehir sularına karışmasından kaynaklandığı düşünülmektedir.

\section{Tartışma ve Sonuç}

Su kalitesinin yönetimi son zamanlarda yapılan en önemli çevresel aktivitelerden biridir. Su kalitesinin belirlenmesinde kullanılan indikatörler, su kalite parametrelerinin ve ülkede belirtilen yönetmelik sinır değerlerinin entegrasyonu ele alınarak belirlenmektedir. Rutin olarak yapılan su kalite izleme programları, birçok değişkenin korelasyonu ve istatistiksel olarak yorumlanmasını gerektiren kompleks yapıda programlardır. Farklı su kalite indeks modelleri, çok fazla veri setine ihtiyaç duymakla beraber, su kaynaklarının yönetiminde etkili ve kolay olarak kullanılabilen yararlı yöntemlerden birdir. 
Tablo 5. Numune alma noktası bazında O SKİ değerlerinın aylık değișimi.

\begin{tabular}{|c|c|c|c|c|c|c|c|c|c|c|c|c|}
\hline$\#$ & Aralık & Ocak & Şubat & Mart & Nisan & Mayıs & Haz. & Tem. & Ăgu. & Eylül & Ekim & Kasım \\
\hline \multirow[b]{2}{*}{1} & 26,248 & 25,906 & 49,939 & 25,594 & 54,648 & 57,841 & 61,033 & 25,798 & 72,683 & 62,930 & 25,627 & 25,937 \\
\hline & Ç. Kötü & Ç. Kötü & Ç. Kötü & Ç. Kötü & Ç. Kötü & Ç. Kötü & Kötü & Ç. Kötü & Kötü & Kötü & Ç. Kötü & Ç. Kötü \\
\hline \multirow{2}{*}{2} & 43,058 & 26,288 & 51,199 & 26,758 & 62,532 & 71,546 & 80,560 & 70,637 & 67,184 & 61,326 & 58,865 & 50,962 \\
\hline & Ç. Kötü & Ç. Kötü & Ç. Kötü & Ç. Kötü & Kötü & Kötü & Uygun & Kötü & Kötü & Kötü & & Kötü \\
\hline \multirow[b]{2}{*}{3} & 25,673 & 26,203 & 72,907 & 26,487 & 62,604 & 71,309 & 80,014 & 26,612 & 26,381 & 52,988 & 69,450 & 47,561 \\
\hline & Ç. Kötü & Ç. Kötü & Kötü & Ç. Kötü & Kötü & Kötü & Uygun & Ç. Kötü & Ç. Kötü & Ç. Kötü & Kötü & Ç. Kötü \\
\hline \multirow[b]{2}{*}{4} & 62,972 & 54,719 & 73,048 & 26,725 & 26,696 & 51,068 & 75,440 & 66,757 & 42,361 & 62,120 & 77,695 & 70,334 \\
\hline & Kötü & Ç. Kötü & Kötü & Ç. Kötü & Ç. Kötü & Ç. Kötü & Kötü & Kötü & Ç. Kötü & Kötü & Kötü & Kötü \\
\hline \multirow{2}{*}{5} & 65,109 & 27,123 & 65,927 & 26,594 & 58,020 & 68,514 & 79,009 & 72,117 & 56,102 & 71,372 & 73,583 & 69,346 \\
\hline & Kötü & Ç. Kötü & Kötü & Ç. Kötü & Ç. Kötü & Ç. Kötü & Kötü & Kötü & Ç. Kötü & Kötü & Kötü & Kötü \\
\hline \multirow{2}{*}{6} & 19,621 & 64,878 & 43 & & & & 97 & & 78 & 48 & 26,610 & 23,115 \\
\hline & Ç. Kötü & Kötü & Ç. Kötü & Ç. Kötü & Ç. Kötü & Ç. Kötü & Kötü & Ç. Kötü & Kötü & Ç. Kötü & Ç. Kötü & Ç. Kötü \\
\hline \multirow[b]{2}{*}{7} & 19,589 & 47,887 & 26,443 & 53,254 & 65,898 & 70,442 & 74,985 & 56,205 & 57,868 & 44,492 & 52,802 & 36,196 \\
\hline & Ç. Kötü & Ç. Kötü & Ç. Kötü & Ç. Kötü & Kötü & Kötü & Kötü & Ç. Kötü & Ç. Kötü & Ç. Kötü & Ç. Kötü & Ç. Kötü \\
\hline
\end{tabular}

Bu çalışmada, Aksaray ili içme su kaynaklarından biri olan Karasu Nehri üzerinde belirlenen 7 noktadan (şehir yaşamının ve sanayinin etkileyebileceği alanlara yakın olan bölgelerde) farklı mevsimleri kapsayacak şekilde her ay alınan örnekler ulusal yönetmeliklerimize ve 3 farklı su kalite indeks modeline göre (USV SKİ, KÇBK SKİ ve O SKİ) irdelenmiştir.

İçme Suyu Elde Edilen veya Elde Edilmesi Planlanan Yüzeysel Suların Kalitesine Dair Yönetmelik sınır değerlerini ortalama konsantrasyonları aşan parametrelerin NH4-N, BOİ, Co ve fekal koliform olduğu tespit edilmiştir. Su kaynağında bu kirletici parametrelerin yüksek konsatrasyonlarda bulunmasının temel sebebinin kaçak evsel ve endüstriyel deşarjlar olduğu düşünülmektedir. Bu sebeple nehir üzerinde bulunan kaçak deşarj noktalarının tespit edilerek önlenmesi önem arz etmektedir. Bu kirletici unsurların nehir sularından giderimi su kaynağının içme suyu temini amacıyla kullanılabilirliğini sağlayacaktır.

Bunun yanı sıra YSKYY baz alınarak su kalitesi incelendiğinde mevsimsel değişimlerin $\mathrm{NO}_{2}, \mathrm{NO}_{3}, \mathrm{~B}$, Cd, Co, Zn ve fekal koliform konsantrasyonlarını olumsuz etkilemesi neticesinde su kaynağının kalite sınıfı III ve IV'e kadar düştüğü tespit edilmiştir.

Karasu Nehrinde kurak ve yağışlı dönemlerin her ikisinde nitrit, nitrat ve organik kirliliğe rastlanmıştır Karasu Nehrinde organik madde değerlerinin yüksek olması suyun kaynak bölgesinin sulak alan özelliğine sahip olmasıyla açılklanabilir.

Elhatip ve Koçyiğit, Karasu Nehrinin döküldüğü Mamasın Barajında 2014-2015 yılları arasında yapmış oldukları çalışmada azot türleri ve organik kirliliğin oluşumunun ziraat kaynaklı olduğu yorumunu yapmışlardır [31].

Tüm parametrelerin ortak değerlendirilmesi üzerine sonuç veren USV SKİ ve O SKİ modelleri sayesinde su kaynağının mevsimsel olarak değerlendirilebilmesini sağlamıştır. Ayrıca KÇBK SKİ modeli kirletici bazında sonuç veren, su kalitesine hangi parametrenin hangi düzeyde etki ettiğinin tespit edildiği ve parametreye göre alınması gereken önlemleri sunan bir modeldir. Alınan model sonuçlarına göre, Karasu nehrinin USV SKİ modeline göre "orta" derece, O SKİ modeline göre "kötü" seviyede olduğu sonucu ortaya çıkmıştır. KÇBK SKİ modeline göre bazı parametrelerde (Al, Cd, $\mathrm{Pb}, \mathrm{Zn}$, çözünmüş oksijen) "marjinal", ölçülen diğer parametrelerde ise (As ve fekal koliform) "kötü" seviyede olduğu belirtilmiştir. Ichwana vd., (2016), Krueng Tamiang nehrinin su kalite modellemesi için USV SKI modelini kullanmışlardır ve yaptıkları çalışmada "orta" ve "kötü" seviyede bulmuşlardır [22]. Abdel-Satar vd., (2017) Nil nehrinin modellenmesinde KÇBK SKİ modelini kullanarak, su kalitesinin kötü seviyede olduğunu belirtmişlerdir [32]. Effendi vd., (2015), Ciambulawung nehrinin USV SKİ modeline göre kalitesini değerlendirdiklerinde, su kalite sınıfının "iyi" seviyede olduğunu belirtmişlerdir [33]. Al-Janabi vd., (2012), KÇBK SKİ modelini Tigris nehrinin modellenmesinde kullanmıșlardır ve su kalitesinin "kötü" durumda olduğunu ve insani tüketim için uygun olmadığını belirtmişlerdir [34].

SKİ modelleri, genel değerlendirme ya da kirletici bazda değerlendirmeye göre belirlenmesi gibi farklı amaçlarla kullanılabilir, çok fazla istatistiki yorum ve izleme programlarına gerek duyulmadan kullanılabilecek modellerdir.

\section{Teșekkür}

Çalışma boyunca laboratuvar imkanlarından yararlandığımız Aksaray Üniversitesi Çevre Mühendisliği Bölümü'ne ve su örneklerinin toplanmasına verdiği desteklerden ötürü Aksaray Belediyesi'ne teşekkür ederiz.

\section{Kaynakça}

[1] Katyal, D., 2011. Water quality indices used for surface water vulnerability assessment, International Journal of Environmental Sciences, 2,1 . 
[2] Almeida, C., Quintar, S., González, P., Mallea, M., 2008. Assessment of irrigation water quality. A proposal of a quality profile, Environmental Monitoring and Assessment, 142, 1-3, 149-152.

[3] Debels, P., Figueroa, R., Urrutia, R., Barra, R., Niell, X., 2005. Evaluation of water quality in the Chillán River (Central Chile) using physicochemical parameters and a modified water quality index, Environmental Monitoring and Assessment, 110, 1-3, 301-322.

[4] Abbasi, S. A., 2002. Water quality indices, state of the art report. Scientific Contribution No. INCOH/SAR, 25.

[5] Kannel, P. R., Lee, S., Lee, Y.-S., Kanel, S. R., Khan, S. P., 2007. Application of water quality indices and dissolved oxygen as indicators for river water classification and urban impact assessment, Environmental Monitoring and Assessment, 132, 1-3, 93-110.

[6] Lumb, A., Halliwell, D., Sharma, T., 2006. Application of CCME Water Quality Index to monitor water quality: A case study of the Mackenzie River basin, Canada, Environmental Monitoring and Assessment, 113, 1-3, 411-429.

[7] Sharifi, M., 1990. Assessment of surface water quality by an index system in Anzali basin, Proceedings of the Hydrological Basis for Water Resources Management, Beijing, 163-171.

[8] Jena, V., Dixit, S., Gupta, S., 2013. Assessment of water quality index of industrial area surface water samples, International Journal of ChemTech Research, 5, 1, 278-283.

[9] Poonam, T., Tanushree, B., Sukalyan, C., 2013. Water quality indices-important tools for water quality assessment: a review, International Journal of Advances in Chemistry, $1,1,15-28$.

[10] Horton, R. K., 1965. An index number system for rating water quality, Journal of Water Pollution Control Federation, 37, 3, 300-306.

[11] Terrado, M., Barceló, D., Tauler, R., Borrell, E., de Campos, S., 2010. Surface-water-quality indices for the analysis of data generated by automated sampling networks, TrAC Trends in Analytical Chemistry, 29, 1, 40-52.

[12] Pitkänen, T., Paakkari, P., Miettinen, I.T., Heinonen-Tanski, H., Paulin, L., Hänninen, M.L., 2007. Comparison of media for enumeration of coliform bacteria and Escherichia coli in nondisinfected water. Journal of Microbiological Methods, 68(3), pp.522-529.

[13] Fricker, C.R., Bullock, S., Murrin, K., Niemela, S.I., 2008. Use of the ISO 9308-1 procedure for the detection of $\mathrm{E}$. coli in water utilizing two incubation temperatures and two confirmation procedures and comparison with defined substrate technology. Journal of water and health, 6(3), pp.389-397.

[14] American Public Health Association, American Water Works Association, Water Pollution Control Federation and Water Environment Federation, 1915. Standard methods for the examination of water and wastewater (Vol. 2). American Public Health Association..

[15] Brown, R. M., McClelland, N. I., Deininger, R. A., Tozer, R. G., 1970. A Water Quality Index- Do We Dare,

[16] Bhargava, D.S., Saxena, B.S., Dewakar, A., 1998. A study of geopollutants in the Godavary river basin in India, Asian Environment.

[17] Tyagi, S., Sharma, B., Singh, P., Dobhal, R., 2013. Water quality assessment in terms of water quality index, American Journal of Water Resources, 1, 3, 34-38.

[18] Fernández, N., Ramírez, A., Solano, F., 2004. Physico-Chemical Water Quality Indices-A Comparative Review-, Bistua Revista De La Facultad De Ciencias Basicas, 2, 1.

[19] Dunnette, D. A., 1979. A geographically variable water quality index used in Oregon. Journal (Water Pollution Control Federation), pp.53-61.

[20] Kumar, D., Alappat, B. J., 2009. NSF-water quality index: does it represent the experts' opinion? Practice Periodical of Hazardous, toxic, and radioactive waste Management, 13, 1, 75-79.

[21] Mitchell, M. K., Stapp, W. B., Beebe, A., 1986. Field manual for water quality monitoring: an environmental education program for schools, Thomson-Shore.

[22] Ichwana, I., Syahrul, S., Nelly, W., 2016. Water quality index by using national sanitation foundation-Water quality index (NSF-WQI) method at krueng tamiang aceh, International Conference on Technology, Innovation, Universitas Syiah Kuala, Indonesia,

[23] Canadian Council of Ministers of the Environment, 2002. Canadian environmental quality guidelines (Vol. 2). Canadian Council of Ministers of the Environment.

[24] Khan, A. A., Paterson, R., Khan, H., 2003. Modification and application of the CCME WQI for the communication of drinking water quality data in newfoundland and labrador, 38th, Central Symposium on Water Quality Research, Canadian Association on Water Quality, 10-11.

[25] Khan, A. A., Tobin, A., Paterson, R., Khan, H., Warren, R., 2005. Application of CCME procedures for deriving site-specific water quality guidelines for the CCME Water Quality Index, Water Quality Research Journal, 40, 4, 448-456. 
[26] Kankal, N., Indurkar, M., Gudadhe, S., Wate, S., 2012. Water quality index of surface water bodies of Gujarat, India, Asian J. Exp. Sci, 26, 1, 39-48.

[27] Dede, Ö. T., Sezer, M., 2017. Aksu çayı su kalitesinin belirlenmesinde Kanada su kalitesi indeks (CWQI) modelinin uygulanması, Journal of the Faculty of Engineering \& Architecture of Gazi University, 32, 3.

[28] Dinius, S., 1987. Design of an Index of Water Quality ${ }^{1}$, JAWRA Journal of the American Water Resources Association, 23, 5, 833-843.

[29] Cude, C. G., 2001. Oregon Water Quality Index a Tool for Evaluating Water Quality Management Effectiveness $^{1}$, JAWRA Journal of the American Water Resources Association, 37, 1, 125-137.

[30] Karami, B., Dhumal, K., Golabi, M., Jaafarzadeh, N., 2009. Optimization the relationship between Water quality index and physical and chemical parameters of water in Bamdezh Wetland, Iran, Journal of Applied Sciences, 9, 21, 3900-3905.

[31] Elhatip, H., Koçyiğit, H., 2016. Environmental Effects of Water Quality of Melendiz Stream and Mamasin Dam Site in Aksaray City in the Central Anatolia of Turkey, Journal of Agricultural Science Technology A, 6, 372-385.

[32] Abdel-Satar, A.M., Ali, M.H. and Goher, M.E., 2017. Indices of water quality and metal pollution of Nile River, Egypt. The Egyptian Journal of Aquatic Research, 43(1), pp.21-29.

[33] Effendi, H., Wardiatno, Y., 2015. Water quality status of Ciambulawung River, Banten Province, based on pollution index and NSF-WQI. Procedia Environmental Sciences, 24, pp.228-237.

[34] Al-Janabi, Z.Z., Al-Kubaisi, A.R., Al-Obaidy, A.H.M.J., 2012. Assessment of water quality of Tigris River by using water quality index (CCME WQI). Al-Nahrain Journal of Science, 15(1), pp.119-126. 